ALPHA No 26 / Julio 2008 (135-152)

ISSN 0716-4254

http://alpha.ulagos.cl

\title{
PASIÓN Y RAZÓN EN THOMAS HOBBES
}

\author{
Passion and Reason in Thomas Hobbes
}

\author{
Jorge Alfonso Vargas* \\ Alex Espinoza Verdejo**
}

\section{Resumen}

Se busca determinar la relación entre pasión y razón en Thomas Hobbes, pensador inglés considerado racionalista tanto como irracionalista. Para explicar esta aparente paradoja, se examinan las nociones de pasión y razón en el contexto de la filosofía materialista y fisicalista de Hobbes y asimismo, la conexión con el nominalismo y el sensualismo. Se demuestra, así, que las pasiones son el principio del movimiento en los hombres y que el pensamiento está a su servicio. Se describe el proceso racional constituyente de una nueva lógica, la del cálculo o la computación. Se concluye que ambos temas, al parecer, no están claramente conectados en la obra de Hobbes a pesar de su intento por hacer del poder, la pasión más fuerte, aquélla que pueda introducir orden en el pensamiento.

Palabras Claves: Razón, pasión, imaginación, entendimiento.

\section{Abstract}

The study determines the relationship between passion and reason in Thomas Hobbes. The English thinker is considered as a rationalist as well as an irrationalist. To explain this apparent paradox, the authors review his notions of passion and reason in the context of his materialistic and physicalistic philosophy. As well as, the connection with his nominalism and sensualism. Passions are shown as the principle of movement in men, thought being at its service. The rational process is described as part of a new logic, the one of calculus, or computation. The conclusion is that both topics are not clearly connected in Hobbes's work despite his effort of making power, the strongest passion, the one that can introduce order in thought.

Key Words: Reason, passion, imagination, understanding.

Thomas Hobbes es considerado un pensador racionalista. Más aún, el fundador del iusracionalismo moderno. Sin embargo, también, aunque en menor medida, se le considera un irracionalista, un pasional afín al voluntarismo de Schopenhauer o Nietzsche ¿Qué sucede con Hobbes? ¿En verdad, hay una contradicción al interior del sistema? Al parecer sí la hay. Sin embargo, lo que sucede, más bien, es que hay una relación especial entre pasión y razón en Hobbes que altera las nociones comunes de la época y 
Jorge Alfonso - Alex Espinoza

nuestra propia idea del hombre como un ser racional y que, si no es una contradicción, al menos es una paradoja.

Nuestro estudio tratará de establecer la relación entre pasión y razón en la filosofía de Hobbes para determinar si realmente hay una conexión entre ellas y cuál es el lazo que une estas dos realidades del alma humana que siempre se han visto como en pugna y que, por lo mismo, hacen de nuestra existencia el teatro de una batalla a la que no sabemos bien si asistimos como espectadores, actores o estrategas. El estudio de las consecuencias de su doctrina materialista y fisicalista servirá para determinar la coherencia del sistema y además, para establecer el vínculo entre pasión y razón al interior de esta filosofía.

La filosofía de Hobbes, pensador antimetafísico por excelencia, tiene su propia metafísica o philosophia prima como él prefiere llamarla. ${ }^{1}$ Sus principios absolutos son la materia y el movimiento. Todo lo que existe es materia (matter); lo que no es materia no existe, matter is what matters, finalmente. La materia, eso sí, no es un principio puramente intelectivo como parece serlo en Aristóteles. Con este término, Hobbes se refiere a la materia, figurada, localizada, y numerada, de los cuerpos existentes aquí y ahora. El cuerpo, por su parte, es el substrato de los accidentes que percibimos y que, al venir a presionar nuestros órganos de los sentidos, dejan como huella las imágenes, los fantasmas de Hobbes, que permanecen en nosotros cuando las cosas ya no están presentes. Por eso, para algunos se debería hablar más bien de corporalismo que de materialismo en Hobbes.

Los cuerpos externos (bodies) que están en movimiento vienen, entonces, a presionar nuestros sentidos y a provocar un cambio físico al interior de nuestro cuerpo, lo que - a su vez- es el origen de nuestras sensaciones, percepciones y, eventualmente, de nuestro conocimiento. Todo esto sucede porque en la naturaleza todo está, o es, en última instancia, movimiento. Materia y Movimiento es, entonces, todo lo que Hobbes necesita para explicar los fenómenos naturales, humanos o sociales con una misma ciencia física. En este contexto, el hombre es un ser natural más; forma parte de la physis hobbesiana; no es un ser que se distinga del resto de los seres naturales $y$, en consecuencia, debe entendérsele en los mismos términos que cualquier otro ente natural más. La continuidad entre el movimiento natural y

\footnotetext{
${ }^{1}$ Este artículo se basa en el Leviatán de Hobbes en su versión en inglés en The English Works of Thomas Hobbes Vol. III. Germany: Scientia Verlag Aalen, 1966. Citaremos así: 3 (volumen): $1,2 \ldots$ (páginas). Las traducciones son nuestras.
} 
las pasiones de un hombre es tal que casi no deja lugar a una diferencia específica que salve al hombre y lo haga lucir como un ser especial. ${ }^{2}$

Pero volvamos al tema del movimiento como causa única y al hombre como un ser natural más. Las pasiones son en Hobbes el principio de los movimientos voluntarios al interior del hombre. Esta concepción fisicalista de las pasiones está conectada con el sensualismo hobbesiano en el plano epistemológico donde el conocimiento empieza con las impresiones sensoriales que alteran los órganos de los sentidos, y de ahí el movimiento continúa en las imágenes o fantasmas (phantasms) de la mente para pasar, luego, a la imaginación o fantasía (fancy), para así —con estas imágenesconstituir un pensamiento basado en la sucesión de las imágenes. Los sentidos, a su vez, dejan en la mente una huella, las imágenes, sensaciones debilitadas por el paso del tiempo, los fantasmas. La imaginación está, así, constituida por las imágenes, resto de pasadas impresiones sensibles. En este punto es bueno advertir que Hobbes parece no poder o no querer distinguir entre imaginación y pensamiento; y el pensamiento, a su vez, parece ser una pura sucesión de imágenes en la memoria nada más. Según Hobbes

En relación a los pensamientos del hombre, yo los consideraría primero individualmente y después en sucesiones o en dependencias unos de otros. Individualmente, cada uno es una representación o apariencia, de alguna cualidad $u$ otro accidente de un cuerpo fuera de nosotros, que es comúnmente llamado un objeto. Dicho objeto impresiona los ojos, oídos, y otras partes del cuerpo humano y por la diversidad de estas impresiones producen la diversidad de las apariencias (3: 1).

La imagen es, entonces, una sensación desvaída por el paso del tiempo; y el pensamiento, una sucesión de imágenes en la memoria, cada una de las cuales es una representación o apariencia de un objeto fuera de nosotros. ${ }^{3}$

Ahora bien, toda imagen provoca pasiones; la realidad no nos es indiferente; los sentimientos de placer o de dolor son nuestra primera reacción

\footnotetext{
${ }^{2}$ Salvo el intento de Hobbes por encontrar en la capacidad de anticipar los posibles efectos de los fenómenos conocidos la diferencia que permite distinguir al hombre del resto de los seres vivos, diferencia que no sabemos bien si la ve como cuantitativa o cualitativa porque no se pronuncia al respecto; o en realidad no le importa, dado su empeño por explicar al hombre como un ser natural más.

3 ¿Materialismo o idealismo? Sin duda, Hobbes es un pensador materialista; pero, a veces, se siembran dudas sobre su materialismo y aparece como un idealista que anticipa, incluso, a Kant. En nuestro artículo (1998) “El Espacio en Hobbes: ¿Idealismo o Materialismo?” en Revista de Filosofía, discutíamos a G. B. Herbert su visión proto-kantiana de Hobbes en su artículo "Hobbes's Phenomenology of Space," en que el espacio aparecía casi como una categoría a priori del pensamiento cuando, en verdad, es un ente corporal más, en la terminología hobbesiana: el lugar de los cuerpos.
} 


\section{Jorge Alfonso - Alex Espinoza}

a los estímulos del medio y, de ahí, provienen nuestras pasiones primarias, el placer y el dolor, y sus derivadas secundarias, como el deseo y la aversión, de donde surgen el amor y el odio y, luego, las pasiones terciarias, podríamos decir, como la envidia o la admiración. La imaginación y las pasiones por su naturaleza cambiante y fluida no parecen por sí solas ofrecer alguna garantía de orden o buen sentido ¿Cómo podríamos, entonces, introducir algún orden o sentido en esta sucesión de imágenes, o, cómo pueden las pasiones ser dirigidas a un fin? Las pasiones y su sucesión en la memoria constituyen un discurso pre-verbal pero discurso al fin y al cabo, es decir, una sucesión relativamente ordenada de imágenes que constituyen nuestro pensamiento. Decimos “nuestro pensamiento" para resaltar el carácter psicológico del pensamiento; esto es, el imaginar/pensar es individualista; no se puede pensar o imaginar lo universal, no hay una imagen de la Humanidad, por ejemplo, sino que de un hombre, Sócrates, por ejemplo. ${ }^{4}$ Pero, no nos apartemos del problema del orden interno del discurso imaginario

Esta sucesión de pensamientos (train of thoughts) — sostiene Hobbeses de dos clases: La primera es sin guía, sin diseño, e inconstante; en la cual no hay algún pensamiento apasionado que los gobierne y dirija a los que le siguen, en relación a él mismo, como sucede con el fin o meta de algún deseo, u otras pasiones; en las cuales los pensamientos se dice que vagan, y parecen no relacionados unos con otros, como en los sueños ( $3: 12)$.

Un hombre puede divagar y, entonces, su pensamiento puede ir de un lado a otro como sucede en los sueños. Pero ¿Sucede esto realmente así? Si, incluso, nuestras asociaciones libres parecen tener un patrón oculto que los

\footnotetext{
${ }^{4}$ Hobbes no parece darse cuenta que la afirmación de la imaginación como fuente del conocimiento encierra una aporía: si la imaginación sólo trata con imágenes particulares y el conocimiento es sólo de lo universal ¿Cómo puede la imaginación ser el origen del conocimiento? Hobbes resuelve el problema con su insistencia en que es el lenguaje el medio para tratar con lo universal, aunque esto sea sólo una ilusión causada por el uso de las palabras. Mas aquí se nos plantea otro problema. Si las palabras son lo único universal ¿Cómo nos salvamos del escepticismo sobre la posibilidad de conocer la realidad, tal como es, meta empírica que muchos atribuyen a Hobbes? Afirmación discutible, por lo demás, ya que lo único que Hobbes dice es que sus palabras "coinciden” con la realidad ( $C f r$. nuestro artículo anteriormente citado), no habiendo una explicación de cómo se realiza esta "coincidencia". Tampoco darle a las definiciones un carácter principial deja las cosas muy claras, porque el cómo se obtienen estas definiciones es algo que Hobbes nunca aclara. Hemos insistido en el hecho de que Hobbes nunca le respondió a K. Digby su pregunta sobre cómo se llega a las definiciones correctas. Cfr. (1994) Letter 25, 17/27, January 1637, Hobbes. The Correspondence, y la insistencia de Hobbes en el uso convencional de los términos tampoco ayuda mucho a aclarar cómo se avanza en el conocimiento.
} 
psicoanalistas se esmeran en develar. Incluso el mismo Hobbes, parece darse cuenta de esta realidad ya que, inmediatamente, matiza esta imaginación tan libre de guía advirtiendo que

en este alocado vagar de la mente un hombre puede a menudo percibir el camino recorrido, y la dependencia de un pensamiento con otro. Porque en un discurso de nuestra actual guerra civil ¿qué podría haber sido más impertinente que el preguntar cuál podría ser el valor de un penique romano? (3: 12-13).

La pertinencia en este caso reside en tratar de sugerir que al rey Carlos I se le estaba vendiendo por treinta monedas como a Jesucristo; pero, esto sólo se descubre por asociación libre, como a menudo lo sostenemos, pero ¿Existe realmente una asociación "libre”? Nuestro filósofo se da cuenta de que el recordar no puede ser una pura asociación libre y, por eso, señala que

como no tenemos imaginación alguna que no hayamos percibido antes, como un todo, o como partes, así no tenemos ninguna transición de una imaginación a otra que no hayamos tenido igual en nuestros sentidos. Cuando un hombre piensa en cualquier cosa su próximo pensamiento no es tan casual como parece. Ni ningún pensamiento sucede a otro indiferentemente (3:11).

¿Qué puede ligar, entonces, un pensamiento a otro, de forma tal que una asociación libre no sea tal sino que esté guiada, o sea — como lo sugiere la actual psicología - intencionada? Al tratar de responder a esta pregunta, Hobbes inicia un camino que lo llevará a hilvanar su propuesta como un modo de pensar que es, a la vez, pasional en su origen pero eventualmente dirigido, seducido, por el objeto de sus deseos

como no tenemos imaginación alguna que no hayamos percibido antes, como un todo, o como partes, así no tenemos transición de una imaginación a otra que no hayamos tenido igual antes en nuestros sentidos ( 3:11).

Una sucesión de imágenes es todo lo que podemos recordar. En esta peculiar anámnesis, la memoria se sostiene, según el pensador inglés, en una coherencia de la materia movida que permitiría darle un sentido, una dirección, a la sucesión de imágenes. El orden impuesto a las imágenes, según Hobbes, se asemeja al ejemplo del dedo que mueve el agua derramada sobre una mesa. Sin embargo, de nuevo, uno tiene la sensación de que Hobbes oscila entre una explicación representacional sin sujeto; un puro reflejo del paso de las imágenes ante nuestra vista interior y una posición que admite un 
Jorge Alfonso - Alex Espinoza

cierto sujeto, aunque sea implícitamente “¡El que mueve el dedo justamente!”. No tenemos otra explicación sobre esta renuencia a admitir un hecho —psicológico, tal vez; pero, un hecho al fin y al cabo- que atribuirla a su oposición al cogito cartesiano, a pesar que su doctrina respecto al tema de la sucesión de las imágenes pida a gritos un sujeto que ordene, organice, tales imágenes para que no sea sólo un puro desorden sin sentido alguno. Por eso mismo, podemos decir que, en este punto, Hobbes hace profesión de sensualismo al proponer como base de la ciencia la sucesión sensaciónimaginación-pensamiento. Algo, según él, innato en nosotros y que sólo requiere esfuerzo y dedicación para alcanzar lo deseado. Sus palabras son claras

No hay ningún acto en la mente de un hombre que yo pueda recordar como implantado naturalmente en él que requiera de alguna otra cosa para su ejercicio que simplemente haber nacido un hombre, y vivir con el uso de sus cinco sentidos (...). Puesto que además de los sentidos, y el pensamiento, y la sucesión de pensamientos, la mente de un hombre no tiene ningún otro movimiento (3: 16).

Sin embargo, como la sucesión de imágenes no nos asegura coherencia — puesto que el olvido puede hacernos perder de vista lo vivido-, por eso mismo es necesario detener, fijar, este flujo de imágenes y para eso está el lenguaje. El lenguaje tiene esta función recordatoria, mnemotécnica. Sin él nos sería imposible pensar con coherencia. Mas cuando el lenguaje no es todo lo coherente y claro que podamos requerir, es el método el que puede venir en nuestro auxilio, aunque - según Hobbes - método sea lo que le falta a los hombres. Pero la dificultad que Hobbes parece no advertir es que ningún orden puede venir de un sujeto ausente de su filosofía ¿De dónde podría venir entonces? Al parecer de la voluntad, el deseo más fuerte. Cuando esto sucede, es decir, cuando tiene un sentido y está guiado por una voluntad fuerte, el orden impuesto al discurso mental permite darle un sentido; sentido que puede ser fijado por el lenguaje. Podemos entender, entonces, al discurso mental como el resultado de un pensamiento que ha podido ser puesto en palabras $y$ al entendimiento como el producto de esta secuencia de imágenes.

El entendimiento según Hobbes no sería sino el nombre que ponemos al producto (matemático), resultado de la suma de imágenes. Este entendimiento, no sólo es guiado por la voluntad, que en Hobbes es sólo el deseo más fuerte, sino que está determinado, a su vez, por el lenguaje. Por eso afirma que el entendimiento - que es peculiar al hombre- no es sólo guiado por la voluntad, sino que sus concepciones y pensamientos lo son por “(...) la secuencia y contextura de los nombres de las cosas en afirmaciones, 
negaciones, y otras formas de discurso" (3: 11). Entonces, el discurso verbal es el que articula y ordena el pensamiento y así, eventualmente, ratio est oratio. Pero no nos adelantemos y volvamos a la imaginación y a la memoria. A esta altura de la discusión se hace más patente la conexión entre la imaginación como una forma de recordar lo ya visto y, a su vez, como una manera de pensar mediante imágenes. Parece que el conocer es similar al asistir cada uno a una representación cinematográfica de su propia vida y mirar y ser conmovido por las imágenes que pasan ante sus ojos. ${ }^{5}$

Llega un momento en que la experiencia debe tornarse ciencia, ciencia del diota; ciencia del por qué ciertas secuencias de eventos están conectadas. Entramos, aquí, de lleno al tema de la causalidad. Hobbes prepara el terreno para Hume al determinar las causas como secuencias de imágenes, vale decir, de hechos psicológicos, pero hechos de todas maneras. Claro está que Hobbes no afirma que la causalidad sea una ilusión creada por hábitos mentales como sostiene Hume. Hobbes es un dogmático de nuevo cuño, un filósofo con fe en la razón como el instrumento para comprender cómo suceden las cosas. ${ }^{6}$ En nuestra opinión, Hobbes parece oscilar entre una concepción de causa como secuencia de eventos, otras como explicación del por qué pasan las cosas o, las más de las veces, como producción de un cierto efecto. No obstante, debemos reconocer que introduce una distinción interesante en el tema al sostener que"

la secuencia de pensamientos regulados es de dos clases, cuando de un efecto imaginado buscamos las causas, o medios que lo produjeron; y esto es común al hombre y a las bestias. La otra es, cuando imaginamos cualquier cosa que sea, y buscamos todos los posibles efectos, que pueden por él ser producidos; esto es, imaginamos qué podemos hacer con ello cuando lo tengamos (3:7).

Este tipo de entendimiento que podría ser llamado "prospectivo" — sostiene Hobbes - sólo se halla en el hombre y es lo que lo distingue ya que

el discurso de la mente, cuando es gobernado por un diseño, no es nada más que una búsqueda o la facultad de la invención que los latinos llaman sagarcitas y solertia, una cacería de las causas de algún efecto

\footnotetext{
${ }^{5}$ Quizá eso explique la sensación de realidad que produce el cine y, a lo mejor, Hobbes tiene razón; cuando pensamos que pasan ante nuestros ojos las imágenes de las cosas que nos interesan, siempre dirigidas por un deseo de obtener lo que queremos. Así este pensamiento imaginario, visual, afectivo, pasional y siempre intencionado, es una buena representación del pensamiento real; es decir, no el de los tratados de lógica, sino el de la existencia cotidiana.

${ }^{6}$ Cfr., J. Alfonso. “La metafísica oculta de Hobbes”, en Límite, (9).
} 


\section{Jorge Alfonso - Alex Espinoza}

presente o pasado o, a partir de causas presentes o pasadas, la búsqueda de (sus) efectos (3: 14).

De esta forma, Hobbes diluye la distinción entre la vida contemplativa y la vida activa, ya que los deseos ponen en acción el pensamiento y éste se pone a su servicio y se ordena, incluso, metodológicamente para conseguir lo que se desea. Más aún, la realidad se hace inteligible justamente a la medida de los deseos humanos. ${ }^{7}$

Por lo mismo, la doctrina de las pasiones de Hobbes altera profundamente la tradicional psicología de las facultades o potencias del alma y esto se nota en la manera de definir y de relacionar los conceptos de deliberación, voluntad y libertad, conceptos psicológicos pero, también, éticos. La tradicional idea de deliberación como el examen, previo a la acción — de los pros y los contras de tal acción- realizado por una razón que como un juez juzga qué debe hacerse u omitirse, se transforma en otra cosa cuando, al definirla, Hobbes establece que:

Cuando en la mente del hombre surgen alternativamente los apetitos y temores que conciernen a una y la misma cosa y diversas consecuencias buenas y malas de nuestros actos u omisiones respecto de las cosas propuestas acuden sucesivamente a nuestra mente, de tal modo que a veces sentimos un apetito hacia ellas, otras una aversión, en ocasiones una esperanza de realizarla, otras veces una desesperación o temor de no alcanzar el fin propuesto, la suma entera de nuestros deseos, aversiones, esperanzas y temores, que continúan hasta que la cosa se hace $o$ se considera imposible, eso es lo que llamamos DELIBERACIÓN (3: 47. Las cursivas son nuestras).

La deliberación no es otra cosa, entonces, sino la suma de nuestras pasiones, más bien, el producto —en términos matemáticos- de nuestra suma (o resta) de pasiones. En consecuencia, no tenemos un control sobre ellas. Somos nuestras pasiones podríamos decir con Hobbes y, justamente, “pasión” viene del latín passio, lo que nos pasa. Ortega y Gasset diría que son fenómenos del alma y no del espíritu. En el plano del alma nos pasan cosas sin ser los protagonistas de ellas; en el plano del espíritu, por el contrario, somos dueños de nuestros actos, protagonistas de nuestra vida interior. ¿Podrá, entonces, la voluntad imponerse y darle un orden a estos pleitos pasionales? (1956:V). Podría, si fuera una facultad que pudiéramos ejercer, como se dice, pero la voluntad no es una facultad de la que podamos hacer

\footnotetext{
${ }^{7}$ Cfr., Missner, M. "Hobbes’s Method in Leviathan”, en Journal of the History of Ideas, 38; Weimberger, J. “Hobbes’s Doctrine of Method”, en American Political Review, 69.
} 
uso, el apetito racional de la tradición. La voluntad en Hobbes no es sino otro nombre hipostasiado que nos engaña haciéndonos creer que tenemos un cierto control sobre lo que nos pasa la voluntad en Hobbes no es más que nuestro último deseo, ya que "En la deliberación, el último apetito o aversión, inmediatamente próximo a la acción, o a la omisión de algo, es lo que llamamos VOLUNTAD, el acto, no la facultad, de querer". (3: 48, Las cursivas son nuestras). La voluntad, en consecuencia, no es una facultad sino un acto. Ni siquiera un acto que hacemos sino que nos pasa, ya que es una pasión que se nos impone por su ímpetu, es nuestro último deseo (last will) ¿Qué lugar queda entonces para la libertad? En verdad, la libertad no encuentra un lugar en el mundo de Hobbes ${ }^{8}$, ya que se la concibe sólo como, la ausencia de obstáculos a los movimientos interiores del hombre que seguirán inercialmente en una determinada dirección si nada se pone en su camino.

Entonces, en esta fisio-psicología ¿Cuál es la relación entre el pensamiento y los deseos? Siendo las pasiones el principio de los movimientos interiores del hombre, los principios de su vitalidad diría Ortega, ¿Cuál será, entonces, la relación entre los pensamientos y los deseos? ¿Pensar acerca de ellos, reflexionar sobre su conveniencia o no conveniencia? En ningún caso "Los pensamientos — según Hobbes - son, con respecto a los deseos, como exploradores (scouts) que es preciso situar para que se adelanten y nos adviertan sobre los mejores caminos para alcanzar las cosas deseadas" (3: 59). De esta forma, podemos advertir que los pensamientos están al servicio de los deseos y que éstos mueven al pensamiento ¿Acaso no es cierto que al ver un objeto deseable pensamos o imaginamos cómo obtenerlo en forma totalmente natural?

Por otra parte, cuando deliberamos buscamos el camino más corto hacia la cosa deseada y el camino más corto es el método, en su sentido moderno de procedimiento que asegura resultados, y método es lo que suele faltar a los hombres, según Hobbes. El método tiene que ver, entonces, con los medios para obtener lo que se desea ¿Pero qué hay de los fines? Hablar de los fines conduce al plano ético, al plano del deber ser. Pero, si hasta ahora hemos estado hablando sólo del ser de las cosas naturales y humanas ¿Cómo saltar del ser al deber ser? Dar un salto al plano metafísico tradicional es imposible en la visión monista y fisicalista de Thomas Hobbes, pero no hace

\footnotetext{
${ }^{8}$ No es mero decir que "la libertad no encuentra un lugar en el mundo de Hobbes", ya que las expresiones lugar y mundo son términos en su sistema y, por ende, tienen un sentido determinado: /Mundo/ como el lugar de los cuerpos y /lugar/ como el espacio real, no imaginado. En este contexto el principio de la libertad es un punto, es decir, un lugar sin límites, una ficción útil, ya que en la causalidad natural no hay tampoco lugar para la libertad y, quizá, por eso Kant hizo de ella un principio trascendental.
} 
Jorge Alfonso - Alex Espinoza

falta, ya que tiene reservada una sorpresa a sus lectores: la ética es, también, una ilusión causada por el uso incorrecto de las palabras, ya que Hobbes pasa sin dar saltos de la psicología a la ética cuando afirma que:

lo que de algún modo es objeto de cualquier apetito o deseo humano es lo que con respecto a él se llama bueno. Y el objeto de su odio y aversión malo; y de su desprecio vil e inconsiderable o indigno. Pues estas palabras de bueno, malo y despreciable siempre se usan en relación a la persona que las utiliza. No son siempre y absolutamente tales, ni ninguna regla del bien y del mal puede sacarse de la naturaleza de los objetos mismos sino del individuo (donde no hay Estado) o (en un Estado) de la persona que lo representa (3: 41).

De esta forma, Hobbes confunde la idea del bien o el mal, con el amor o el odio que siente el individuo. De este subjetivismo extremo brota el relativismo moral en que viven los hombres en el estado natural. Relativismo que conduce al conflicto y hasta la guerra de todos contra todos. La guerra no sólo por la propiedad de ciertos bienes sino, también, por sobre quién tiene la razón respecto del bien y del mal, de lo justo o injusto; es decir, sobre quién decide en materia de juicios morales. Los individuos - incapaces de ponerse de acuerdo- con el propósito de poder vivir en paz prefieren convenir en firmar un contrato social que los lleve a establecer a una persona como gobernante para que sea el juez supremo en cuestiones éticas y poner fin de esta manera a los conflictos morales y políticos entre los hombres. La ética es, entonces, una cuestión de conveniencia, que se torna convencional con el tiempo. Y esto es así porque no hay nada en las cosas que permita establecer una regla absoluta. En su estado natural el individuo es la medida de todas las cosas. Sin embargo, es curioso cómo este fundador del derecho natural moderno afirme que no hay nada en las cosas que permita establecer una norma absoluta y que todo en el fondo depende del individuo y, más aún, de sus odios, deseos o aversiones. En resumidas cuentas, de sus pasiones.

Un hombre movido por sus pasiones - y cuyos pensamientos están al servicio de sus deseos - sólo puede ser feliz en la medida que alcance las cosas deseadas. Y, por eso, no es extraño que Hobbes —al definir la felicidad- afirme que:

El éxito continuo en la obtención de las cosas que un hombre desea de tiempo en tiempo, es decir, su perseverancia continua es lo que los hombres llaman felicidad. Me refiero a la felicidad en esta vida; en efecto, no hay cosa que dé perpetua tranquilidad a la mente mientras vivamos aquí abajo, porque la vida raras veces es otra cosa que movimiento y no puede darse sin deseo y sin temor, como no puede 
Pasión y razón en Thomas Hobbes

existir sin sensaciones. Qué género de felicidad guarda Dios para aquellos que con devoción le honran, nadie puede saberlo antes de gozarlo, son cosas que, ahora, tan incomprensibles como ininteligibles parece la frase visión beatífica de los escolásticos (3: 51).

La felicidad no consiste, entonces, ni en la vida contemplativa de los antiguos ni en la beatitud de los cristianos, sino que en el éxito continuo en obtener lo que se desea en esta vida. Esta visión hedonista - “exitista” más bien - parece muy apropiada para describir la idea de felicidad del hombre medio actual pero, en la época de Hobbes, es una visión pobre, errada, del tema; casi una herejía. Sobre todo, porque él mismo se encarga de subrayar su rechazo a las ideas tradicionales de felicidad sencillamente porque son ininteligibles o no se puede tener experiencia de ellas $\dot{¿} Y$, cómo asegurar una vía para alcanzar todo lo que se desea en el futuro? En primera instancia, mediante el conocimiento de la naturaleza, y de la forma cómo funciona esa máquina extraordinaria para imitar a la naturaleza y producir parecidos efectos, ya que como Bacon, su antiguo patrón, había advertido, saber es poder.

El poder es un tema central, para el reconocido fundador del pensamiento político moderno. Sin embargo, en Hobbes el poder no es sólo un tema político, sino un tema humano y social

El poder de un hombre universalmente considerado consiste en sus medios presentes para obtener algún bien manifiesto futuro. Puede ser éste original o instrumental. Poder natural es la eminencia de las facultades del cuerpo o de la inteligencia, tales como una fuerza, belleza, prudencia, aptitud, elocuencia, liberalidad o nobleza extraordinaria. Son instrumentales aquellos poderes que se adquieren mediante los antedichos o por fortuna, y sirven como medios o instrumentos para adquirir más (poder) como la riqueza, la reputación, los amigos o los secretos designios de Dios, lo que los hombres llaman buena suerte (3: 74).

Si el poder consiste en tener, o aparentar tener, ciertos atributos o talentos que permiten obtener más poder y, en consecuencia, más medios para alcanzar lo que se desea, el poder ayuda a la felicidad - ya que ésta no es otra cosa que obtener lo que se desea-; no es extraño, entonces, que la vida moderna sea una loca carrera tras las cosas que deseamos, a rat's race ciertamente ¿ No es esto pasional más que racional? Y, sin embargo, la razón ocupa un lugar importante en el sistema hobbesiano.

¿Hay alguna forma de establecer una conexión entre las pasiones y la razón? Al parecer no la hay. El tema de la razón ocupa un capítulo aparte en 


\section{Jorge Alfonso - Alex Espinoza}

el Leviatán que, si bien viene después del tema de las pasiones, no guarda ninguna conexión lógica con éste. Hobbes define la razón como un cómputo, vale decir, como una suma o resta de nombres o afirmaciones —o, más bien, de las consecuencias de esas afirmaciones-. Se suman o se restan palabras o proposiciones en el plano lógico. Se suman o se restan pactos en el plano político; pero no hay algo así como suma o resta de pasiones en su nueva lógica. En el De Corpore o el De Cive donde se puede decir que Hobbes piensa sumando y restando, Hobbes no parece plantearse una nueva lógica pasional. ${ }^{9}$ Es más, Hobbes parte de una concepción de la lógica que aparece como nueva, ya que tradicionalmente ha sido entendida como el estudio del pensamiento correcto pero éste hace depender la lógica más bien del lenguaje correcto. $^{10}$

La lógica hobbesiana ciertamente es un tema muy extenso. Por lo mismo, para no alejarnos mucho de nuestro estudio vamos a tratar de resumirla. La lógica de Hobbes no es la lógica clásica con sus leyes del pensamiento correcto, sino que es una nueva lógica, la del cálculo: cálculo de las posibilidades de éxito o fracaso en la obtención de lo que se desea. En el caso de las obligaciones políticas, el individuo se está preguntando constantemente si le conviene obedecer la ley o si le es más conveniente no hacerlo. A esta lógica se la ha llamado en política, la lógica del self-interest, también se la ha calificado de egoísta o individualista porque el pensamiento está al servicio de los deseos de cada persona. Hoy día se la podría asimilar al análisis de costo-beneficio tan característico del economicismo actual. ¿Pero cómo se llegó a esto? La razón moderna, según Horkheimer, no se ocupa ya de los principios, no puede ni siquiera intuirlos, se limita simplemente a administrar los medios para alcanzar las cosas deseadas ya que — como lo anticipó- para Hobbes la felicidad del hombre moderno consiste en conseguir siempre lo que desea. Según Horkheimer ésta es una razón

\footnotetext{
${ }^{9}$ J. F. Aguirre Sala, en Hermenéutica. Ética de las Pasiones (2005) intenta conciliar razón y pasión haciendo ver que las pasiones son expresión, de nuestro (bien o mal) estar en el mundo y, que por lo tanto, son significativas, aunque no se expresen en palabras y estén mediadas por gestos o símbolos. Si las pasiones son significativas — puesto que en todo pathos hay poiésisson, a su vez, según Aguirre Sala, verdaderos juicios sobre la realidad, juicios de un sujetopasión y podrían dar origen, incluso, a una ética. Nada similar hay en Hobbes quien, intuyendo que los pensamientos están al servicio de los deseos, no desarrolla más allá esta idea.

${ }^{10}$ Decimos que esta lógica "aparece como nueva” porque la lógica en realidad nunca ha aborrecido el lenguaje. Al contrario, lo ha considerado expresión del pensamiento; pero su fin es realmente establecer la recta consecuencia como una forma válida de pensamiento. Hobbes, en cambio, parece creer que será la reforma del lenguaje la que podrá mejorar la manera de pensar de los hombres. Es este énfasis en el lenguaje el que reduce el pensar a una pura cuestión de palabras y como resultado ratio est oratio.
} 
subjetiva que a diferencia de la clásica, que llama objetiva, se ocupaba no sólo de los medios sino de los fines y de intuir los primeros principios. ${ }^{11}$

Para Hobbes, alcanzar los principios es, en parte, una sustracción de las partes componentes de un cuerpo para llegar, así, a los últimos componentes o primeros principios de éste. Decimos, en parte, porque "el inglés” —como lo llamaba despectivamente Descartes - también acepta categorías a priori como las de Aristóteles, aunque ellas no se acomodan, muy bien, a un modo de pensar que lo reduce al puro imaginar y no admite el intelecto agente entre otras cosas. Aparentemente, Hobbes hace lo mismo que Aristóteles: conocer por las causas y seguir el método del análisis y la síntesis. Sólo que, en Hobbes, "análisis” quiere decir resta, sustracción de partes constituyentes de los todos, y "síntesis", es suma, adición, de estas mismas partes para imaginar cómo recomponer esos todos y entender cómo funcionan. Sumar y restar es todo lo que hace el lenguaje para ayudarnos a pensar. Más aún, los matemáticos están de acuerdo en que todas las operaciones matemáticas son, en última instancia, sumas. Una computadora no es más que una gran máquina sumadora ¿Pero, nos preguntamos, pensar es solamente sumar? Muchos hoy en día piensan que sí; pero nosotros pensamos que ciertamente sumar es pensar; pero pensar no es solamente sumar. ${ }^{12}$

Lo que sucede, nos parece, es que Hobbes se mueve en el plano puramente formal de las sumas y restas de denominaciones, pero pensar no es sólo eso. Pensar no es sólo calcular sino desear, temer, dudar, equivocarse y pensar de nuevo, etc. Es decir, en el pensar nos involucramos totalmente, como seres humanos, inteligentes y sensibles, y los factores emocionales son parte del proceso. Es muy peculiar que un pensador tan pasional en algunos aspectos, cuando de la razón se trata, deje de lado las pasiones y trate al hombre como una fría máquina calculadora. Quizá haya aquí, seguramente la hay, una influencia de la física o de la lógica de Hobbes, ya que ninguna

\footnotetext{
11 "El hecho de percibir — y de aceptar dentro de sí- ideas eternas que sirvieran al hombre como metas era llamado, desde hacía mucho tiempo, razón. Hoy, sin embargo, se considera que la tarea, e incluso la verdadera esencia de la razón, consiste en hallar medios para lograr los objetivos propuestos en cada caso”. Cfr. Horkheimer. Crítica de la Razón Instrumental, 1996.

12 ¿Y si fuera cierto que todo pensar es sólo sumar? En verdad no lo sabemos. Está claro que el cálculo de costo-beneficio hobbesiano es una suma o resta de posibles acciones (obedecer o no obedecer, atreverse o no atreverse, esperar o desalentarse y así) ¿Pero, el pensar mediante de Heidegger es una suma, el efecto que produce es ése? Nos parece que se asemeja, más bien, a una experiencia, la experiencia de la apertura al ser. Pero el tema está abierto. Si las computadoras pueden imitar la inteligencia humana es porque son máquinas sumadoras y Hobbes tendría razón.
} 


\section{Jorge Alfonso - Alex Espinoza}

persona conduce sus pensamientos en una forma tan ordenada, tan racional. ${ }^{13}$ Lo anterior reafirma nuestra idea inicial de una posible contradicción al interior del sistema. Pero, no nos adelantemos, ya que debemos pasar al tema de la lógica de Hobbes para oponerla a la dinámica pasional y explorar la relación entre ésta y el pensamiento lógico.

$\mathrm{Al}$ estudiar la epistemología de Hobbes hay que tener en cuenta el tema del lenguaje, ya que, como advertíamos, todo pensamiento correcto no es sino un lenguaje bien hecho. Según, Hobbes

El uso general del lenguaje es transferir nuestro discurso mental a uno verbal; o la secuencia de nuestros pensamientos, a una de palabras; y esto para una doble comodidad, una la de registrar la consecuencia de nuestros pensamientos, los cuales siendo aptos para abandonar nuestra memoria, y ponernos así a trabajar de nuevo, pueden ser recordados por las palabras que los marcan. Por eso el primer uso de los nombres es el de servir de marcas o notas para recordar. Otro es, cuando muchos usan la misma palabra, para significar, por su conexión y orden, una a otra, lo que ellos conciben, o piensan de cada materia, y también qué desean, temen, o sienten alguna pasión. Y por eso se les llama signos (3: 19-20).

De esta descripción podemos sacar importantes consecuencias para la comprensión del lenguaje. Primero que todo, que el principal uso del lenguaje es transferir el discurso mental al verbal. Lo que, a su vez, nos lleva a preguntarnos si existe un discurso mental preverbal y cómo se constituiría éste ¿Con las imágenes nada más? No estamos seguros qué piensa Hobbes. A veces parece sugerir que el pensamiento es una secuencia de imágenes pero, en otras, que el pensamiento tiene que ser universal como requisito científico; ¡Pero las imágenes son particulares! Todo este embrollo parece provenir del hecho de que en Hobbes el pensamiento, como tal, no se distingue de la sucesión de imágenes en nuestra mente o de las pasiones que estas imágenes despiertan en nosotros. En todo caso, queda claro que el lenguaje permite fijar las sucesiones de imágenes pero, también, advertir las relaciones entre ellas, de forma tal que permite pasar de un discurso preverbal a uno verbal que articula, ordena la realidad. Pero, como a su vez no queda muy claro cómo este discurso verbal se transforma en pensamiento, da la impresión que razonar será — de aquí en adelante — una cuestión de palabras ya que

\footnotetext{
${ }^{13}$ Que pensar sea sólo computar, es una idea ciertamente moderna, no siempre ha sido así y los filósofos han discutido esta visión reduccionista del pensar. Cfr. D. Parrochia, Qu'est-ce penser/calculer? Paris, Vrin,1992.
} 
Pasión y razón en Thomas Hobbes

Cuando un hombre razona no hace sino concebir una suma total a partir de adiciones de partes, o concebir un resto de la substracción de una suma de otra, la cual si es hecha con palabras es el concebir las consecuencias que los nombres de todas las partes tienen para con los nombres del todo; o de los nombres del todo y una parte, con relación a otra parte (3: 29).

Razonar sería, entonces, sumar y restar (otra forma de sumar) y se puede sumar no sólo números, sino que en geometría, líneas y figuras; en lógica, consecuencias del uso de las palabras y, en política, pactos entre los hombres. Por eso, tiene razón Hobbes en que, aparente y etimológicamente, ése es el verdadero significado de lo que hace el silogismo. De esta idea brota lo que llamamos conocimiento racional. Pero, éste no es sólo un mirar como pasan las cosas ante nuestros ojos sino que, siendo natural en nosotros, requiere un cierto cultivo para captar la racionalidad tras los eventos, puesto que, según Hobbes

la razón no es, como los sentidos y la memoria, algo innato, ni conseguido con la experiencia solamente, como lo es la prudencia, sino obtenida por el esfuerzo, primero en imponer en forma apropiada los nombres; y segundo, consiguiendo un buen y ordenado método en el proceder desde los elementos, que son los nombres, a afirmaciones hechas conectando unos con otros; y así hasta los silogismos, que son las conexiones de una afirmación con otra hasta llegar al conocimiento de todas las consecuencias de los nombres que pertenecen al tema en cuestión; y esto es lo que los hombres llaman CIENCIA (3: 35).

Tal podría ser el propósito de todos los grandes constructores de sistemas que tienen como principios ideas claras y distintas, como Descartes o, en este caso, definiciones convencionales como Hobbes. A esto nos referimos cuando decimos que el pensamiento científico de Hobbes es sólo un lenguaje bien hecho, bien construido. Pero, si razonar tiene como propósito no sólo ser consistente consigo mismo, sino que entender la realidad. ¿Qué es, entonces, el entendimiento? El entendimiento en Hobbes es el producto (la suma) de todos los elementos que constituyen el proceso cognoscitivo que hemos venido describiendo, ya que

"Cuando un hombre al oír cualquier discurso tiene esos pensamientos que las palabras de ese discurso y sus conexiones tenían como propósito significar, entonces se dice que lo entiende, el entendimiento viene a ser entonces nada más que la concepción causada por el lenguaje” (3: 28). 
Jorge Alfonso - Alex Espinoza

El lenguaje, entonces, produce conocimiento en la medida que el entendimiento es una concepción causada por el lenguaje.

Hobbes pareciera no estar consciente del verdadero poder del lenguaje como medio expresivo y permanecer atrapado en las redes de un lenguaje puramente convencional que se limita a poner nombres a las cosas para no olvidarlas. Esto - eso sí- en el plano lógico, científico, porque en el plano artístico, en el plano de la literatura, Hobbes es un maestro del lenguaje y emplea recursos retóricos con propósitos artísticos, pero también persuasivos a la luz de lo que Skinner afirma (2004). Lo que revela una cierta inconsistencia entre el Hobbes humanista —y su confianza en la experiencia y la literatura como medio para conocer la realidad-y el Hobbes científico nuevo que trata de construir un sistema coherente y consistente sobre la base de un método que sólo admite un procedimiento deductivo a partir de definiciones correctas. El tema está abierto y ha estado recibiendo atención últimamente (Astorga, 2000).

La contradicción en el sistema parece estar entre una antropología irracionalista y una política racionalista, ya que un individuo privado de razón, voluntad y libertad a la luz de su psicología no puede tomar las decisiones racionales que se suponen están en la base del contractualismo. La inconsecuencia está en que un hombre sometido a sus pasiones no puede darle legitimidad a ningún gobierno. Las pasiones, advertíamos, son pasajeras, cambiantes y muy poco de fiar, aunque se reconozcan como muy efectivas. ${ }^{14}$ Quizá aquí haya que volver a lo que buscábamos resolver. ¿Hay algún principio que pueda poner orden a las pasiones? Hobbes parece encontrarlo en el poder. El poder sería el que unifica y dirige nuestras pasiones y el poder no es nada más que un deseo fuerte de dominar, una cupiditas dominandi presente en algún grado en todos los hombres, de forma tal que estos parecen dividirse entre los que tienen un gran deseo de poder - los ambiciosos- y los que no tienen ningún deseo de poder —los pusilánimes- que prefieren vivir una vida tranquila y dejarse gobernar por otros. Pero Hobbes no se decide a constituir una antropología ni sobre la base de esta cupiditas ni sobre la base del miedo a la libertad de los débiles o pusilánimes.

En buenas cuentas, Hobbes parece no poder decidirse entre una concepción del hombre como un ser pasional que se mueve por impulsos, y la de un ser racional que delibera sobre los pros y los contras de sus posibles

\footnotetext{
${ }^{14}$ Este problema tiene relación con el fundamento último de la ética hobbesiana. Según Deigh, este fundamento es tema de una controversia entre quienes creen que el fundamento es psicológico, el egoísmo hobbesiano, y los que ve en ella una deontología basada en el poder absoluto de Dios. Deigh añade su propia visión — definicionista, podríamos llamarla — en que el fundamento está en las definiciones, es una cuestión lingüística.
} 
acciones, pudiendo haber intentado construir una lógica pasional-racional a partir de su intuición de que los pensamientos se adelantan a nuestros deseos en búsqueda de las cosas que deseamos tener. El problema pasa al parecer, finalmente, por la incapacidad de Hobbes de establecer una conexión entre pasión y razón, de forma tal que podamos entender el hombre puede llegar desde ciertas pasiones a la claridad racional necesaria para establecer normas objetivas y obligarse a cumplirlas. La razón dicta normas, las leyes de la naturaleza, como resultado de una inferencia basada en las pasiones — sostiene Hobbes - , pero si la deliberación no es otra cosa sino una pugna pasional en que la pasión más fuerte es nuestra última voluntad, se entiende que la solución al conflicto natural no pueda ser otro que el establecimiento de un poder absoluto.

\author{
Universidad de Tarapacá* \\ Facultad de Educación y Humanidades \\ 18 de Septiembre 2222, Campus Saucache \\ Arica (Chile) \\ jalfonso@uta.cl \\ Universidad de Tarapacá** \\ Facultad de Ciencias Sociales y Jurídicas \\ 18 de septiembre 2222, Campus Saucache \\ Arica (Chile) \\ aespinoz@uta.cl
}

\title{
BIBLIOGRAFÍA
}

AGUIRRE SALA, J. F. Hermenéutica. Ética de las Pasiones. Salamanca: Sígueme, 2005.

ALFONSO, Jorge. “El Espacio en Hobbes: ¿Idealismo o Materialismo?”, en Revista de Filosofía, LI, LII. Santiago, Universidad de Chile, (1998):68-85.

“La Metafísica Oculta de Hobbes”, en Límite (9), Arica, Universidad de Tarapacá, (2002):48-72.

ASTORGA, Omar. "La idea de imaginación en algunos textos de la literatura crítica hobbesiana”, en Nota Bibliográfica. Boletín de la Asociación de Estudios Hobbesianos. Argentina, $N^{\circ}$ 21, Verano, (2000).

J. DEIGH. "Reason and Ethics in Hobbes's Leviatán", en Journal of the History of Philosophy, Jan: 34, 1, (1996):33-60.

GIANNINI, Humberto. La Experiencia Moral. Santiago: Universitaria, 1992. 
Jorge Alfonso - Alex Espinoza

HERBERT, G. B. “Hobbes's Phenomenology of Space”, en Journal of the History of Ideas, 48, (1987):709-717.

HOBBES, Thomas. English Works III. Germany: Scientia Verlag Aalen, 1966.

HORKHEIMER, Mark. Crítica de la Razón Instrumental. Buenos Aires: SUR, 1996.

MISSNER, Marshall. "Hobbes's Method in Leviathan", en Journal of the History of Ideas Vol. 38, (Oct-Dec) No 4, (1997): 607-621.

ORTEGA Y GASSET, José. "Vitalidad, Alma y Espíritu”, en Obras Completas Vol. 5, Madrid: Revista de Occidente, 1956.

PARROCHIA, D. Qu'est-ce Penser/Calculer. Paris: Vrin, 1992.

MALCOLM, I. N. (ed.). Hobbes. The Correspondence. Oxford: Claredon Press, 1994.

SAMPSON, George. (1970) The Concise Cambridge History of English Literature. Cambridge University Press, 1970.

SKINNER, Quentin. Reason and Rhetoric in the Philosophy of Hobbes. Cambridge University Press, 2004.

URBAN, W. M. Lenguaje y Realidad. México: F.C.E., 1952.

WEIMBERGER, J. "Hobbes's Doctrine of Method", en American Political Science Review. Vol. 69, №4 (Dec., 1975), 1997:1336-1353. 